\title{
Production of serine protease inhibitors by mutagenesis and their effects on the mortality of Aedes aegypti L. larvae
}

Tatiane Sanches Soares ${ }^{1}$, Ricardo José Soares Torquato1, Yamile Gonzalez Gonzalez ${ }^{1}$, Francisco Jose Alves Lemos ${ }^{2}$ and Aparecida Sadae Tanaka ${ }^{1 *}$

\begin{abstract}
Background: Dengue, transmitted primarily by the bites of infected Aedes aegypti L., is transmitted to millions of individuals each year in tropical and subtropical areas. Dengue control strategies are primarily based on controlling the vector, using insecticides, but the appearance of resistance poses new challenges. Recently, highly selective protease inhibitors by phage display were obtained for digestive enzymes of the 4th instar larvae (L4) midgut. These mutants were not confirmed as a larvicide due to the low yield of the expression of these inhibitors. In the present study, chimera molecules were constructed based on the mutations at positions P1-P4' selected previously. The T6, T23 and T149 mutants were mixed with another Kunitz inhibitor, domain 1 of the inhibitor boophilin (D1).

Methods: The chimeras T6/D1, T149/D1 and T23/D1 were expressed at high levels in P. pastoris yeast, purified by ionic exchange chromatography and their homogeneity was analyzed by SDS-PAGE. The chimera inhibitors were assayed against larval trypsin, chymotrypsin and elastase using specific chromogenic substrates. The inhibitors were assayed for their larvicide potential against L4.

Results: The chimeras exhibited strong inhibitory activities against the larval digestive enzymes in a dose-dependent manner. T6/D1, T149/D1 and T23/D1 exhibited strong larvicidal activity against L4 of Ae. aegypti with inhibitor concentrations in the $\mu \mathrm{M}$ range. A synergistic increase in mortality was observed when a mixture of the three chimeric inhibitors was tested.

Conclusions: The strategy for constructing the chimeric inhibitors was successful. The chimeras showed strong larvicidal activity against Ae. aegypti. In the future, our findings can be used to design synthetic inhibitors for larvae digestive enzymes as an alternative method to control the dengue vector.
\end{abstract}

Keywords: Mosquito, Serine protease inhibitor, Larvae, Aedes aegypti, Larvicide

\section{Background}

Aedes aegypti (Linnaeus) is the primary vector of several arboviruses including dengue, yellow fever and chikungunya $[1,2]$. Aedes aegypti is well adapted to urban areas, and represents a major problem for public health [2]. An estimated 500,000 people with severe dengue are hospitalized each year, and approximately $2.5 \%$ die [3]. Unfortunately, there is no vaccine or treatment for dengue

\footnotetext{
* Correspondence: tanaka.bioq@epm.br

'Departamento de Bioquímica, Escola Paulista de Medicina, Universidade Federal de São Paulo, Rua 3 de Maio 100, 04044-020 São Paulo, SP, Brazil Full list of author information is available at the end of the article
}

available, and vector reduction remains the main method for reducing the transmission of the dengue virus [3].

Digestive enzymes present in Ae. aegypti larvae include trypsin-like, chymotrypsin-like and elastase-like serine proteases [4]. A transcriptional analysis of the trypsinlike enzymes present in the midgut of laboratory-reared Ae. aegypti was performed, and the key enzyme, a native trypsin, was purified and characterized [4].

The trypsin inhibitor from Moringa oleifera flowers (MoFTI) interferes with the survival and development of Ae. aegypti larvae. Mortality of newly hatched larvae (L1) was observed in the presence of the M. oleifera flower extract and MoFTI [5]. A lectin from M. oleifera 
seeds (WSMoL) was shown to kill Ae. aegypti L4 by causing morphological alterations in the digestive tract and inhibition the digestive enzymes [6].

Recently, phage display was performed using a selection of inhibitors to the larvae digestive enzymes [7]. A library of mutants was constructed using the inhibitor HiTI as a template, and the reactive site region, $\mathrm{P} 1$ to $\mathrm{P} 4$ ', of the inhibitor was randomized. The HiTI mutants that showed strong inhibitory activity were T6 for trypsin and T23 and T149 for both chymotrypsin and elastase. As the HiTI mutants' expression in yeast was very low, it was not possible to evaluate their larvicidal activity.

The strategy adopted in this work was to insert the mutations at positions $\mathrm{P} 1$ to P4' of HiTI, T6, T23, and T149, into domain 1 of the thrombin inhibitor boophilin [8], which exhibited high levels of expression in P. pastoris yeast. The new chimera molecules were designated mutants T6/D1, T23/D1, and T149/D1 and were produced and tested as larvicide for Ae. aegypti larvae. As the mosquito larvae is confined to and continuously feeds in aquatic environments [9], inhibition of the digestive enzymes present at this stage of life could be a useful strategy to control the mosquito populations.

\section{Methods}

Cloning and expression of the inhibitors in Pichia pastoris For this work, we constructed chimeric inhibitors in which the region P1-P4' of the selected inhibitors by phage display previously [7] was cloned substituting this region in the domain 1 of the boophilin inhibitor (D1) (Fig. 1), which has a high level of protein expression. As the boophilin inhibitor domain 1 (D1 wild) had been cloned previously in our laboratory in pPICZaB plasmid this construction $\mathrm{D} 1$ wild/pPICZ $\alpha \mathrm{B}$ was used as a template for PCR reactions. To replace the P1-P4' region (reactive site) of the inhibitor boophilin $\mathrm{D} 1$ by this region of the inhibitors T6, T23 and T149, were designed internal oligonucleotides flanking this region for each inhibitor. The internal oligonucleotides sequences used were: T6D1IntFw 5'-CAAGGC ATCTGCCGCGGTGGTGCCGTGCGCTTCTACTTC-3'; T6D1IntRv 5'-GAAGTAGAAGCGCACGGCACCACC GCGGCAGATGCCTTG-3'; T23D1IntFw 5'-CAAGGCAT CTGCCTACTAGGTGGTCTACGCTTCTACTTC-3'; T23 D1IntRv 5'-GAAGTAGAAGCGTAGACCACCTAGTAGG CAGATGCCTTG-3'; T149D1IntFw 5'CAAGGCATCTG CGGTGGTGTGTGGCGCCGCTTCTACTTC-3' e T149D 1IntRv 5'-GAAGTAGAAGCGGCGCCACACACCACCG CAGATGCCTTG-3'. The DNA amplifications by PCR were performed in two steps: firstly, DNA was amplified the initial region of the inhibitors until the reactive site containing the substitutions (AOX5' and D1IntRv oligonucleotides), and secondly, it was amplified the region of the reactive site containing the substitutions until the end of the inhibitors (D1IntFw and AOX3' oligonucleotides), construction D1 wild/pPICZ $\alpha$ B was the template for both. Afterwards, the two DNA fragments were united by a PCR reaction using primers $\mathrm{AOX} 5$ ' and $\mathrm{AOX}^{\prime}$ flanking region of the initial and end of the inhibitors, this procedure was made to each mutant. Purified DNA fragments were digested with $X h o \mathrm{I}$ and NotI restriction enzymes and ligated into the pPICZ $\alpha$ B vector, (Invitrogen, Carlsbad, CA, EUA) previously digested with the same restriction enzymes. The resulting constructs were used in the transformation of bacteria E. coli DH5- $\alpha$, purified, sequenced and verified. The constructs were used to transform yeast $P$. pastoris strain GS115 by electroporation. To identify positive yeast clones expressing each of the inhibitors, five clones from $P$. pastoris strain GS115 containing the insert of each inhibitor, identified and verified by PCR (AOX5' and AOX3' oligonucleotides), were individually inoculated in $2.5 \mathrm{~mL}$ of BMGY medium (Buffered Glycerol-complex Medium) $(1.0 \%(\mathrm{w} / \mathrm{v})$ yeast extract, $2.0 \%(\mathrm{w} / \mathrm{v})$ peptone in $100 \mathrm{mM}$ potassium phosphate buffer, $\mathrm{pH}$ 6.0, $1.34 \%(\mathrm{w} / \mathrm{v}) \mathrm{YNB}, 4 \times$ $10^{-5} \%(\mathrm{w} / \mathrm{v})$ biotin and $1 \%(\mathrm{v} / \mathrm{v})$ glycerol) in a $50 \mathrm{~mL}$ sterile tube and incubated at $30{ }^{\circ} \mathrm{C}$ for $28 \mathrm{~h}$ at $250 \mathrm{rpm}$. The yeast cells were harvested by centrifugation at $3000 \times g$ for $5 \mathrm{~min}$ at $4{ }^{\circ} \mathrm{C}$, and resuspended in BMMY medium (Buffered Methanol-complex Medium) (BMGY with glycerol replaced by $0.5 \%(\mathrm{v} / \mathrm{v})$ methanol) to an absorbance of 1.0 at $600 \mathrm{~nm}$. Proteins were expressed at $30{ }^{\circ} \mathrm{C}$ with shaking at $250 \mathrm{rpm}$, for $96 \mathrm{~h}$ with the addition of $0.5 \%(\mathrm{v} / \mathrm{v})$ methanol every $24 \mathrm{~h}$. After removing the cells by centrifugation $\left(4000 \times g\right.$ for $20 \mathrm{~min}$ at $\left.4{ }^{\circ} \mathrm{C}\right)$, the supernatants were assessed for their ability to inhibit bovine chymotrypsin, bovine trypsin or neutrophil elastase using enzymatic assays and the following specific chromogenic substrates: TosylGly-Pro-Arg-pNA for trypsin, Suc-Ala-Ala-Pro-PhepNA for chymotrypsin and Suc-Ala-Ala-Pro-Val-pNA for elastase. Individual clone expressing high levels of each inhibitor was selected. A single P. pastoris colony (Mut+) expressing high level of the mutants T6/D1, T23/D1 T149 and $\mathrm{D} 1$ wild was selected and used to inoculate $120 \mathrm{~mL}$ of BMGY medium in a $1 \mathrm{~L}$ sterile flask, which was then further incubated at $30{ }^{\circ} \mathrm{C}$ and $250 \mathrm{rpm}$ for $24 \mathrm{~h}$. Protein expression was performed as described above, and the supernatant of the culture was stored at $-20{ }^{\circ} \mathrm{C}$.

\section{Purification of the inhibitors T6/D1, T23/D1, T149/D1 and D1 wild}

The expression supernatants $(\sim 1 \mathrm{~L})$ of the inhibitors T6/ D1, T23/D1, T149/D1 and D1 wild were dialyzed with 0.04 M Tris-HCl, $\mathrm{pH}$ 8.0, and applied to ion exchange chromatography on HiTrap Q column. The inhibitors ( $200 \mathrm{~mL}$ supernatant per chromatography) were purified using ion exchange chromatography on HiTrap Q column (GE, Fairfield, CT, EUA), connected to a medium pressure chromatography system ÄKTA Prime, 


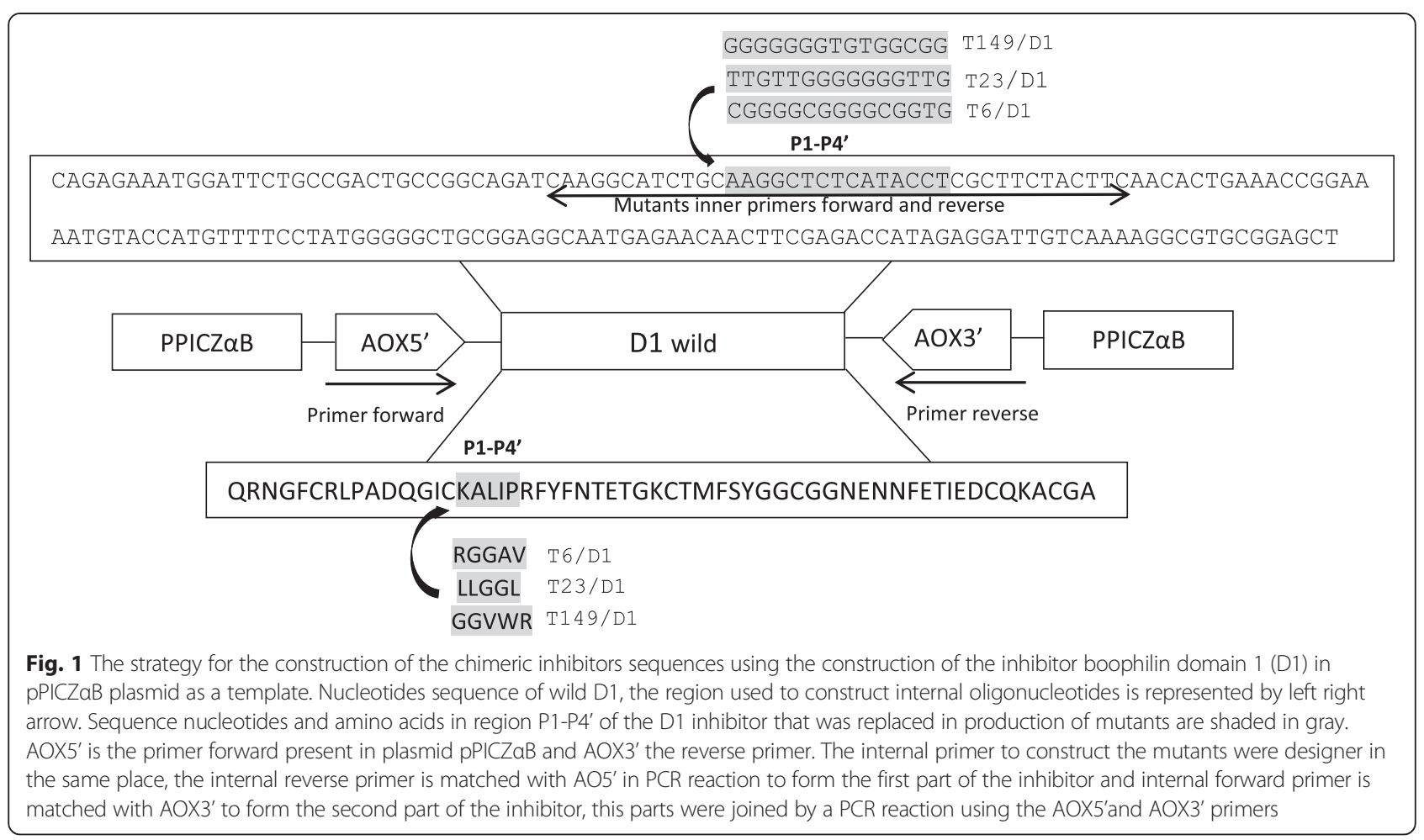

previously equilibrated with $0.05 \mathrm{M}$ Tris- $\mathrm{HCl}, \mathrm{pH}$ 8.0. After washing, the proteins were eluted using a $\mathrm{NaCl}$ linear gradient $(0-1 \mathrm{M})$ in $0.05 \mathrm{M}$ Tris- $\mathrm{HCl}, \mathrm{pH} 8.0$, at flow rate $1.5 \mathrm{~mL} / \mathrm{min}$ for $60 \mathrm{~min}$. Flow through and eluted fractions from the HiTrap Q column were tested for inhibitory activities to trypsin (T6/D1 and wild D1) and elastase (T23/D1 and T149/D1) using the chromogenic substrates Tosyl-Gly-Pro-Arg-pNA, and SucAla-Ala-Pro-Val-pNA, respectively. Purified inhibitors were concentrated and analyzed by $15 \%$ SDS-PAGE gels [10].

Larvicidal activity assay using the mutants T6/D1, T23/D1, T149/D1 and D1 wild

Adult Ae. aegypti colonies (Rockefeller strain) were reared in cages, at $27{ }^{\circ} \mathrm{C}$ and provided of $10 \%$ sucrose solution in distilled water. A glass container filled with distilled water was kept inside each cage to maintain the humidity. Larvae were maintained in distilled water and fed on a minced commercial mouse food. The fourth (L4) instar larvae were used in the experiments. For the assay, groups of $15 \mathrm{~L} 4$ were placed in $5 \mathrm{~mL}$ of distilled water containing the following total protein concentrations of the mutants T6/D1 (111-588 $\mu \mathrm{M})$, T23/D1 (79-858 $\mu \mathrm{M})$, T149/D1 $(64-684 \mu \mathrm{M})$ and D1 wild (64-684 $\mu \mathrm{M})$. The lethal concentrations required for killing $50 \%$ of Ae. aegypti larvae $\left(\mathrm{LC}_{50}\right)$ after 24 and $48 \mathrm{~h}$ were calculated by probit analysis with a reliability interval of $95 \%$ using the StatPlus 2006 software
(AnalystSoft, Vancouver, BC, Canada). The experiments were performed in triplicate and monitored at $24 \mathrm{~h}$ and $48 \mathrm{~h}$. ANOVA $(p<0.05)$ and the Tukey's test used in the statistical analysis were calculated using GraphPad Prism version 4.0 for Windows (GraphPad Software, San Diego, CA, USA).

Inhibitory activity assay of mutant inhibitors T6/D1, T23/ D1, T149/D1 for larvae serine proteases

Larvae midgut extract $(0.8 \mathrm{mg}$ total protein was used for trypsin and chymotrypsin and $24.5 \mathrm{mg}$ for elastase) was pre incubated with different concentrations of the inhibitors T6/D1, T23/D1, T149/D1 in 0.1 M Tris/HCl (pH 8.0) containing $0.1 \%$ Triton X-100 for $10 \mathrm{~min}$ at $37^{\circ} \mathrm{C}$. Afterwards, residual enzymatic activities were measured at $405 \mathrm{~nm}$ by adding Suc-Ala-Ala-Pro-Val-pNA, Tosyl-GlyPro-Arg-pNA and Suc-Ala-Ala-Pro-Phe-pNA as chromogenic substrates for neutrophil elastase, trypsin and chymotrypsin, respectively.

\section{Results}

\section{Cloning, expression and purification of the chimeric} inhibitors

Amino acids at positions P1-P4' of D1 (KALIP) were replaced by the amino acids presented at those positions in the mutants T6 (RGGAV), T23 (LLGGL) and T149 (GGVWR), selected previously by phage display. The nucleotide sequences of T6/D1 (Fig. 2a), T23/D1 (Fig. 2b), and T149/D1 (Fig. 2c) clones in the pPIZ $\alpha B$ 


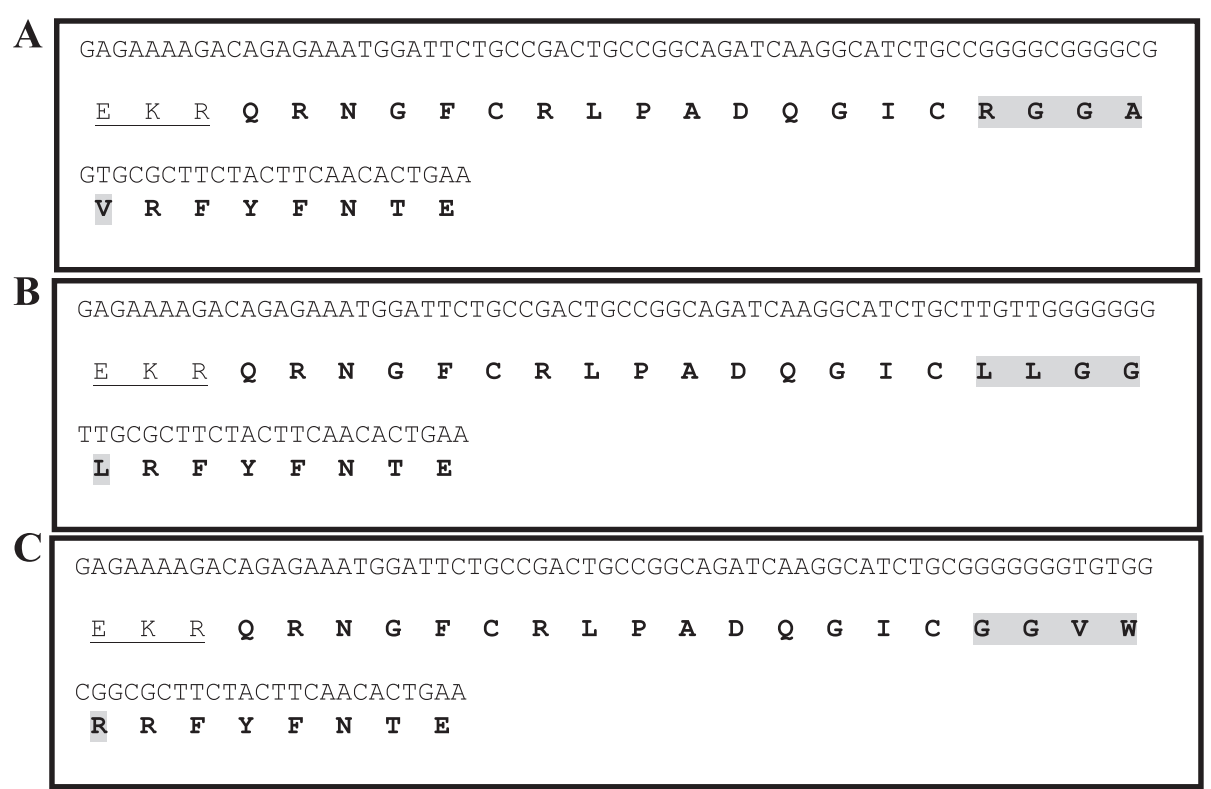

Fig. 2 Nucleotides and traduced amino acid sequences of the chimera cloned in the pPICZaB vector. a. Mutant T6/D1; b. Mutant T23/D1; c. Mutant T149/D1. The sequence of PPICZaB vector is underlined, and the mutated regions (P1-P4') of the inhibitors are shown in gray

vector were confirmed by PCR amplification followed by DNA sequencing. Mutants T6/D1 (Fig. 3a), T23/ D1 (Fig. 3b), T149/D1 (Fig. 3c) and wild D1 (Fig. 3d) were purified by ion exchange chromatography and by SDS-PAGE confirmed the homogeneity of the inhibitors (Fig. 4a).
Inhibitory activity of the mutants for larval serine proteases All mutants showed inhibitory activity against larvae digestive enzymes in a dose-dependent manner (Fig. 4b). T6/D1 was able to inhibit larval trypsin-like enzymes, and T23/D1 and T149/D1 both inhibit chymotrypsinlike and elastase-like enzymes.
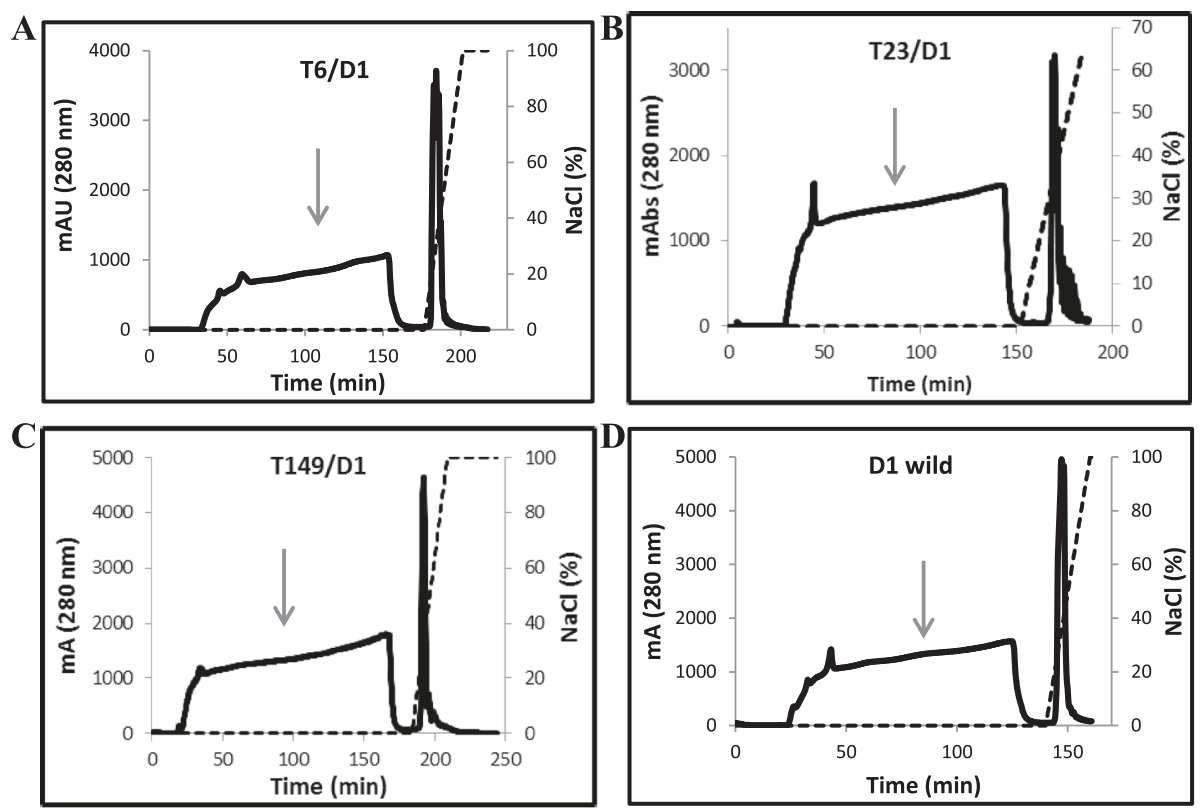

Fig. 3 Purification of the chimeras T6/D1, T149/D1, T23/D1 and D1 wild expressed in P. pastoris by ion exchange chromatography in HiTrap Q column. The supernatant of the culture medium dialyzed with $0.05 \mathrm{M} \mathrm{Tris/HCl} \mathrm{pH} 8.0$ buffer was applied in the column pre equilibrated with the same buffer. The elution of proteins was performed with a linear gradient of $\mathrm{NaCl}(0-1 \mathrm{M})$. The regions containing inhibitory activities are indicated by gray arrows 

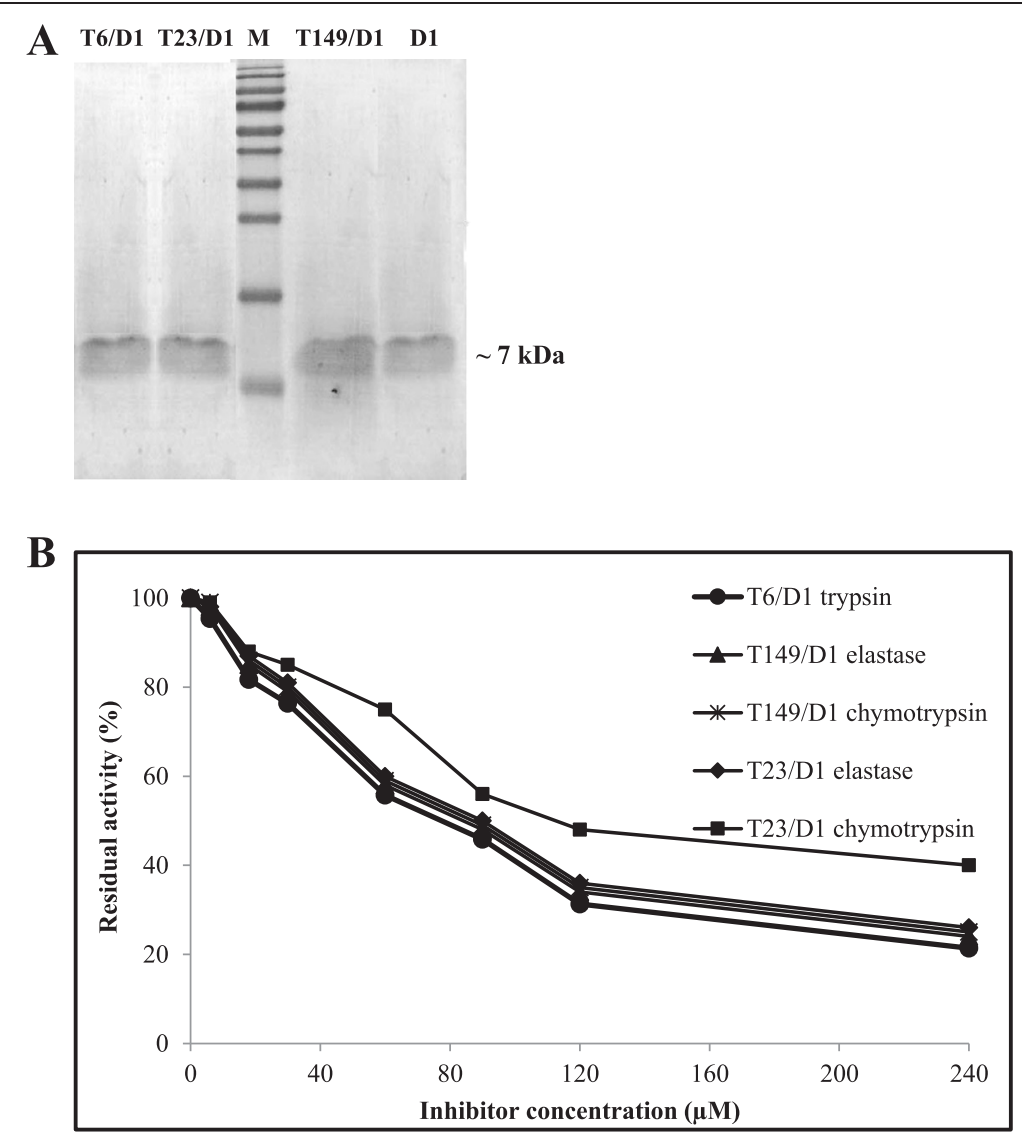

Fig. 4 Characterization of the mutants: T6/D1, T23/D1, T149/D1 and D1 wild. a SDS-PAGE (15\%) of the flow through of the ion exchange chromatography in HiTrap Q column of the mutants T6/D1, T23/D1, T149/D1 and D1 wild. $\mathbf{b}$ Inhibition assay of the chimeric inhibitors for larvae serine proteases. Enzymatic activities using the L4 midgut extract of Ae. aegypti and chromogenic substrate for trypsin (Tosyl-Gly-Pro-Arg-pNA), chymotrypsin (Suc-Ala-Ala-Pro-Phe-pNA) and elastase (Suc-Ala-Ala-Pro-Val-pNA). Both trypsin and chymotrypsin assays were performed using $0.8 \mathrm{mg}$ total protein, and $24.5 \mathrm{mg}$ total protein for elastase

\section{Larvicidal assays using mutants T6/D1, T23/D1, T149/D1 and wild D1}

Larvicidal potential of the mutant inhibitors and wild D1 were evaluated on L4 larvae. The mutant T6/D1 showed $100 \%$ of mortality against L4 at $350 \mu \mathrm{M}$ after $24 \mathrm{~h}$. At $302 \mu \mathrm{M}$, mutant T6/D1 showed approximately $40 \%$ mortality in L4 larvae after 48 h (Fig. 5a). The LC 50 values determined for T6/D1 were of $380 \mu \mathrm{M}$ and $302 \mu \mathrm{M}$ for larvae after $24 \mathrm{~h}$ and $48 \mathrm{~h}$ of assay, respectively. The mutant T23/D1 presented mortality of 35-95 \% in concentrations between $604 \mu \mathrm{M}$ to $858 \mu \mathrm{M}$, at $48 \mathrm{~h}$ (Fig. $5 \mathrm{~b}$ ). The $\mathrm{LC}_{50}$ values for T23/D1 were of $1.1 \mathrm{mM}$ and $611 \mu \mathrm{M}$ for larvae after $24 \mathrm{~h}$ and $48 \mathrm{~h}$, respectively. At $24 \mathrm{~h}$, the mutant T149/D1 showed 18-80 \% mortality of L4 larval between the concentrations $413 \mu \mathrm{M}$ to $684 \mu \mathrm{M}$. At $48 \mathrm{~h}$, mortality increased to $60-100 \%$ (Fig. $5 \mathrm{c}$ ). The $\mathrm{LC}_{50}$ values for T149/D1 were of $577 \mu \mathrm{M}$ and $421 \mu \mathrm{M}$ for larvae after $24 \mathrm{~h}$ and $48 \mathrm{~h}$, respectively. A synergic effect was observed when mutant T6/D1 $(238 \mu \mathrm{M})$, T23/D1 $(198 \mu \mathrm{M})$ and T149/D1 $(286 \mu \mathrm{M})$ were mixed together and tested against L4 Ae. aegypti larvae, at concentrations that individually none of the inhibitors presented larvicidal effect, all together showed $100 \%$ mortality (Fig. 5e).

The wild D1 showed larval mortality of $27-93 \%$ at $270 \mu \mathrm{M}$ to $684 \mu \mathrm{M}$, respectively at $24 \mathrm{~h}$. The estimated $\mathrm{LC}_{50}$ for D1 were of $474 \mu \mathrm{M}$ for larvae after $24 \mathrm{~h}$. At 48 h, the L4 mortality was 60-100 \% (Fig. 5d). All inhibitors were used in assays against $\mathrm{L} 1$, at the same concentrations used in the assays for L4 Ae. aegypti larvae, but larvicidal activity was not observed (data not showed).

\section{Discussion}

The advance in integrated pest management has been caused by most cost-effective methods and commonsense practices for control of pests that represent a low hazard to the environment and people [11]. Phage display is a powerful technique used to study protease inhibitors [12-14]. Recently, our group used phage display system and the inhibitor HiTI [15] to select specific inhibitor for digestive enzymes of Ae. aegypti larvae [7]. In this work, based on data of Soares et al. [7], the mutated regions (residues P1-P4') of selective HiTI mutated 

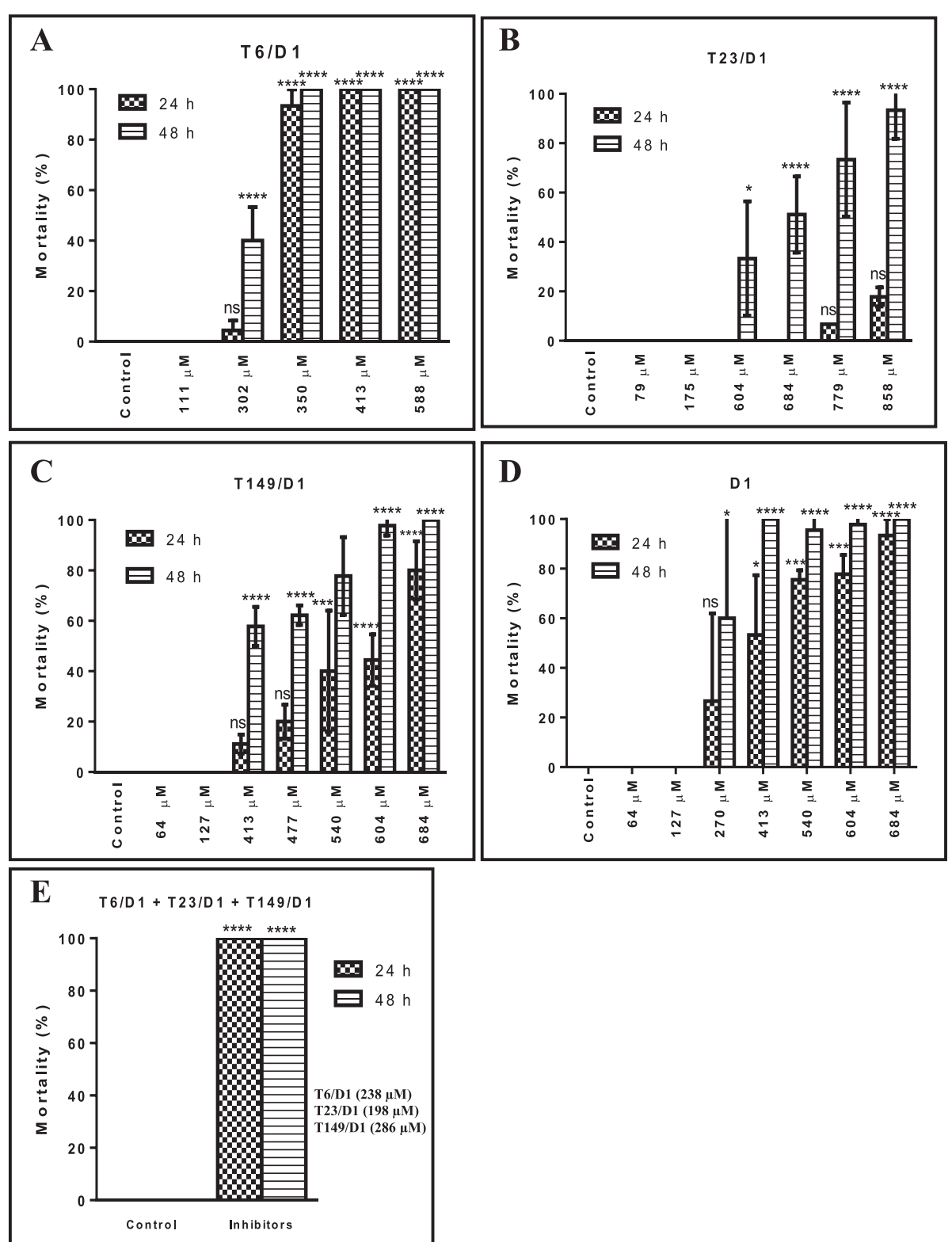

Fig. 5 Larvicidal effect of chimeric inhibitors against L4 Ae. aegypti larvae, in 24 h and 48 h assays. a. Mutant T6/D1; b. Mutant T23/D1; c. Mutant T149/D1; d. D1 wild; e. Assay with combination of the mutants T6/D1, T23/D1 and T149/D1. The experiments were performed in triplicate using experimental group containing 15 larvae each. The larval mortality level of the inhibitors was significant increase when compared to control $\left(^{*} p<0.05\right.$, ${ }^{* *} p<0.01,{ }^{* *} p<0.001,{ }^{* * *} p<0.0001$ and ns-not significant, in Tukey's Multiple Comparison Test). ANOVA $(p \leq 0.05)$ and Tukey's analysis were used for statistical analysis. Error bars correspond to the standard error of the mean of three experiments

inhibitors identified for digestive enzymes Ae. aegypti larvae were inserted into another Kunitz domain inhibitor, to increase the level of recombinant protein expression. The template inhibitor selected was the boophilin inhibitor domain 1 (D1) of Rhipicephalus microplus. Previously, boophilin domain 1 had been cloned and expressed by our group and shown to a high protein expression level of approximately $20 \mathrm{mg} / \mathrm{L} \mathrm{[8].} \mathrm{The}$ chimeric molecules, named mutants HiTI T6, T23 and T149, were selected by strong inhibition activity of digestive enzymes of Ae. aegypti larvae, presenting $\mathrm{IC}_{50}$ in $\mathrm{nM}$ range [7].

The continuous and indiscriminate use of synthetic insecticides has led to emergence resistant Ae. aegypti populations, environmental persistence and unselective toxicity [16]. Natural insecticides have been investigated for larvicidal effect on Ae. aegypti resistant strains because they are usually available at low cost, are usually highly biodegradable, and the larvae usually do not develop cross-resistance to them, minimizing resistance 
development [17]. Thus, alternative methods and new strategies for vector control need to be developed. Purified proteins from plants have been demonstrated larvicidal activity against Ae. aegypti. Many plant insecticides primarily target the midgut of the mosquito larvae, and some are able to interfere with the larval development into adult stage. A trypsin inhibitor (MoFTI) purified from Moringa oleifer flowers caused mortality of hatched newly larvae [5]. And, a lectin extracted from M. oleifera seeds (WSMoL) was able to kill L4 Ae. aegypti by causing morphological alterations in the larvae digestive tract and inhibition digestive enzymes [6]. A lectin from Myracrodruon urundeuva leaf showed effect on survival and digestive enzymes activity from Ae. aegypti larvae [18]. Essential oils from Brazilian Croton species showed larvicidal activity against Ae. aegypti [16]. So, the production of highly selective inhibitors for the digestive enzymes from Ae. aegypti larvae by mutagenesis presents itself as an innovative approach in this area of study.

The enzymes present in the gut of larvae of Ae. aegypti responsible for its digestion are trypsin-like, chymotrypsinlike and elastase-like serine proteases [7, 19]. In the present work, the mutant T6/D1, a trypsin inhibitor, in the concentration of $350 \mu \mathrm{M}$ caused the highest mortality (100 \%) in L4 Ae. aegypti. This results corroborate the data that, tryp$\sin$ is the major enzyme presents in the midgut of $A e$. aegypti, being the main responsible for digestion in larvae [7] and the impairment of its activity may result in poor nutrient absorption and non-availability of essential amino acids. The mutant T23/D1, also showed larvicidal effect against L4, but its effect was only observed after $48 \mathrm{~h}$ with mortality rates of 50-93\%. The mutant T149/D1 showed larval mortality of $60-100 \%$ at $48 \mathrm{~h}$ of exposure. T149/D1 was more effective as larvicide than T23/D1. These data support our hypothesis that T149/D1 may have been selected not only to the digestive enzymes but also to other molecules present in the larval midgut that are important for the larvae larval physiology. As T23/D1 and T149/D1 are inhibitors of the chymotrypsin and elastase enzymes that are apparently in low concentration in the larvae, which are in consonance with lower larvicidal effect than T6/D1.

In an attempt to evaluate the synergic effect in the inhibition of all enzymes present in midgut, the three mutants T6/D1, T23/D1 and T149/D1 were added in a larvicidal assay. Surprisingly, the concentration of each inhibitor used in the blend not caused mortality when used separately, but in combination, they caused $100 \%$ L4 mortality. Confirming that, the inhibitors efficiency was higher when all digestive enzymes present in the midgut were inhibited in the same time. None of the three mutants presented larvicidal effect against L1 Ae. aegypti, confirming the specific-targeting power of phage display selection system to effect only L4 larval.
To remove any doubt regarding the specificity of the inhibitors in the larvicidal assay, the wild D1 inhibitor was used in the larvicidal experiments. However, only wild D1 caused mortality of approximately $50 \%$ of L4 compared with $100 \%$ mortality obtained for the T6/D1 and not mortality for the T23/D1, at the same concentration. D1 was used as a control since only its reactive site was removed for construction of chimeras. As inhibitor D1 wild is a strong bovine trypsin inhibitor, it was expected some effect on larval survival, but the results support our conclusion that the mutant selection was specific for the 4th larval instar and that trypsin-like enzymes are important for larval physiology.

For the first time highly selective inhibitors have been selected specifically for digestive enzymes from $A e$. aegypti larvae. The chimeric inhibitors may have impaired digestive and absorption processes in the midgut of Ae. aegypti larvae compromising their survival.

\section{Conclusions}

Our findings indicate that the mutants selection by phage display were specific for the L4 Ae. aegypti. The mutant inhibitors were efficient in causing larval mortality; and the synergism of mutant inhibitors selected for different digestive enzymes was more effective as larvicide. In the future, these inhibitors can be used in control measures for the larvae of Ae. aegypti mosquito.

\section{Abbreviations \\ D1: Boophilin inhibitor domain 1; T6/D1, T23/D1, and T149/D1: Mutants of the boophilin inhibitor domain 1.}

\section{Competing interests}

All authors declare that they have no competing interests.

\section{Authors' contributions}

TSS performed all assay and data analysis, and drafted the manuscript, RJST and YGG participated in the purification of the inhibitors, and FJAL provided the insect and assisted in the larvicidal assays. AST designed and supervised the study, provided major inputs into the data analysis and provided critical inputs on the manuscript. All authors read and approved the final version of the manuscript.

\section{Acknowledgments}

This work was supported by Fundação de Amparo à Pesquisa do Estado de São Paulo (FAPESP; grants 2009/05405-3, 2009/06003-6, 2005/03514-9 and 2012/

03657-8), CNPq Proc. 575829/2008-7 and INCT - Entomologia Molecular - CNPq, Grant 573959/2008-0.

\section{Author details}

${ }^{1}$ Departamento de Bioquímica, Escola Paulista de Medicina, Universidade Federal de São Paulo, Rua 3 de Maio 100, 04044-020 São Paulo, SP, Brazil. ${ }^{2}$ Laboratório de Biotecnologia, Universidade Estadual do Norte Fluminense, Rio de Janeiro, RJ, Brazil.

Received: 13 December 2014 Accepted: 30 September 2015 Published online: 06 October 2015

\section{References}

1. Johansson MA, Powers AM, Pesik N, Cohen NJ, Staples JE. Nowcasting the spread of chikungunya virus in the Americas. PloS One. 2014;9(8):e104915. 
2. Mackenzie JS, Gubler DJ, Petersen LR. Emerging flaviviruses: the spread and resurgence of Japanese encephalitis, West Nile and dengue viruses. Nat Med. 2004;10(12 Suppl):S98-109.

3. WHO. Dengue and severe dengue. Fact sheet $\mathrm{N}^{\circ} 117$. wwwwhoint/entity/ mediacentre/factsheets/fs117/en/. 2012.

4. Soares TS, Watanabe RM, Lemos FJA, Tanaka AS. Molecular characterization of genes encoding trypsin-like enzymes from Aedes aegypti larvae and identification of digestive enzymes. Gene. 2011;489(2):70-5.

5. Pontual EV, de Lima Santos ND, de Moura MC, Coelho LC, do Amaral Ferraz Navarro DM, Napoleao TH, et al. Trypsin inhibitor from Moringa oleifera flowers interferes with survival and development of Aedes aegypti larvae and kills bacteria inhabitant of larvae midgut. Parasitol Res. 2014;113(2):727-33.

6. Agra-Neto AC, Napoleao TH, Pontual EV, Santos ND, Luz Lde A, de Oliveira CM, et al. Effect of Moringa oleifera lectins on survival and enzyme activities of Aedes aegypti larvae susceptible and resistant to organophosphate. Parasitol Res. 2014;113(1):175-84.

7. Soares TS, Soares Torquato RJ, Alves Lemos FJ, Tanaka AS. Selective inhibitors of digestive enzymes from Aedes aegypti larvae identified by phage display. Insect Biochem Mol Biol. 2013;43(1):9-16.

8. Soares TS, Watanabe RM, Tanaka-Azevedo AM, Torquato RJ, Lu S, Figueiredo $A C$, et al. Expression and functional characterization of boophilin, a thrombin inhibitor from Rhipicephalus (Boophilus) microplus midgut. Vet Parasitol. 2012;187(3-4):521-8.

9. Heintze C, Velasco Garrido M, Kroeger A. What do community-based dengue control programmes achieve? A systematic review of published evaluations. Trans R Soc Trop Med Hyg. 2007;101(4):317-25.

10. Laemmli UK. Cleavage of structural proteins during the assembly of the head of bacteriophage T4. Nature. 1970;227(5259):680-5.

11. Procopio TF, Fernandes KM, Pontual EV, Ximenes RM, de Oliveira AR, Souza Cde S, et al. Schinus terebinthifolius Leaf Extract Causes Midgut Damage, Interfering with Survival and Development of Aedes aegypti Larvae. PloS One. 2015;10(5):e0126612.

12. Tanaka AS, Sampaio CA, Fritz H, Auerswald EA. Functional display and expression of chicken cystatin using a phagemid system. Biochem Biophys Res Commun. 1995;214(2):389-95.

13. Tanaka AS, Silva MM, Torquato RJ, Noguti MA, Sampaio CA, Fritz $\mathrm{H}$, et al. Functional phage display of leech-derived tryptase inhibitor (LDTI): construction of a library and selection of thrombin inhibitors. FEBS Lett. 1999:458(1):11-6.

14. Campos IT, Silva MM, Azzolini SS, Souza AF, Sampaio CA, Fritz H, et al. Evaluation of phage display system and leech-derived tryptase inhibitor as a tool for understanding the serine proteinase specificities. Arch Biochem Biophys. 2004:425(1):87-94.

15. Azzolini SS, Sasaki SD, Campos IT, Torquato RJ S, Juliano MA, Tanaka AS. The role of HiTl, a serine protease inhibitor from Haematobia irritans irritans (Diptera: Muscidae) in the control of fly and bacterial proteases. Exp Parasitol. 2005;111(1):30-6.

16. Lima EP, Paiva MH, de Araujo AP, da Silva EV, da Silva UM, de Oliveira LN, et al. Insecticide resistance in Aedes aegypti populations from Ceara. Brazil Parasit Vectors. 2011:4:5.

17. Simas NK, Lima Eda C, Kuster RM, Lage CL, de Oliveira Filho AM. Potential use of Piper nigrum ethanol extract against pyrethroid-resistant Aedes aegypti larvae. Rev Soc Bras Med Trop. 2007;40(4):405-7.

18. Napoleao TH, Pontual EV, de Albuquerque LT, de Lima Santos ND, Sa RA Coelho LC, et al. Effect of Myracrodruon urundeuva leaf lectin on survival and digestive enzymes of Aedes aegypti larvae. Parasitol Res. 2012;110(2):609-16.

19. Yang YJ, Davies DM. Trypsin and chymotrypsin during metamorphosis in Aedes aegypti and properties of the chymotrypsin. J Insect Physiol. $1971 ; 17(1): 117-31$.

\section{Submit your next manuscript to BioMed Central and take full advantage of:}

- Convenient online submission

- Thorough peer review

- No space constraints or color figure charges

- Immediate publication on acceptance

- Inclusion in PubMed, CAS, Scopus and Google Scholar

- Research which is freely available for redistribution

Submit your manuscript at www.biomedcentral.com/submit 